\title{
Desenvolvendo indicadores estratégicos em ciência e tecnologia: as principais questões ${ }^{*}$
}

\section{Edson Kenji Kondo}

\section{Resumo}

Este trabalho propõe que os indicadores estratégicos para países menos desenvolvidos devem considerar a especificidade desses países, portanto não devendo meramente replicar os indicadores utilizados pela OCDE. Com esse objetivo, usa um novo marco conceitual que destaca a importância do equilíbrio entre a eficiência econômica e o bem-estar social. Enumera vários motivos razoáveis para desenvolver os indicadores estratégicos, mostra como cada um deles é baseado em pressuposições que não necessariamente serão válidas para todos os países e mostra por que é necessário adotar um novo enfoque conceitual. Após discustir as principais características do método proposto, mostra de que maneira este novo marco pode ajudar a identificar os tipos de indicadores necessários. Finalmente, o trabalho sugere de que maneira o enfoque poderá ser útil para um projeto que procura avaliar publicações científicas.

\section{Palavras-chave}

Indicadores em ciência e tecnologia.

\section{INTRODUÇÃO}

À medida que os países intensificam seus esforços para recolher dados e desenvolver indicadores relacionados às atividades científicas e tecnológicas, precisam definir que tipos de indicadores desejam e, portanto, que tipo de dados deverão recolher. A principal fonte de referência nesse campo são os indicadores usados pelos países da Organização para a Cooperação e o Desenvolvimento Econômico (OCDE) e as metodologias que vêm desenvolvendo. Tanto as metodologias como os dados são adequados às suas realidades específicas. Os esforços feitos pelos países não participantes da OCDE deverão considerar as especificidades de seus contextos econômicos, industriais e sociais. Essa não é uma preocupação nova, mas, até o momento, os esforços para criar novos indicadores careciam de um marco conceitual que deslocasse o foco da eficiência econômica dos indicadores existentes em ciência e tecnologia (C\&T) para uma visão mais equilibrada que inclui as dimensões relacionadas ao bem-estar social. Este trabalho tem a intenção de propor de que maneira esse novo marco pode ser útil ao sugerir indicadores de C\&T vinculados ao bem-estar social, além dos indicadores já conhecidos que se referem à eficiência econômica.

\section{RAZÕES ** PARADESENVOLVER INDICADORES ESTRATÉGICOS **}

Que tipos de decisões devem ser tomadas com base nos indicadores de C\&T? Por que precisamos desenvolver indicadores estratégicos? Eles têm algum significado? O que eles nos dizem?

Poderíamos pensar que essas são perguntas formuladas com freqüência pelas pessoas que tomam decisões no governo e em outras áreas. Lamentavelmente, alguns produtores e usuários desses indicadores tendem a ver esses números como representantes de algum tipo de "verdade" sobre o estado da ciência e da tecnologia, e não como possíveis aproximações da realidade. Além do mais, os indicadores somente são úteis se forem confiáveis. Existem outras limitações que discutiremos mais tarde, mas, ao construírmos indicadores confiáveis, devemos considerar as seguintes razões para usá-los:

\footnotetext{
* Trabalho apresentado no Seminário sobre Avaliação da Produção Científica, realizado em São Paulo pelo Projeto SciELO, de 4 a 6 de março de 1998.

** Esta seção faz uso de várias razões apresentadas por Adam Holbrook no Tercer Taller Iberoamericano/Interamericano sobre Indicadores de Ciencia y Tecnologia, realizado de 1 a 3 de outubro de 1997 em Santiago, Chile. Por sua vez, Holbrook creditou algumas dessas razões a Jan van Steen.

*** Neste texto, os indicadores estratégicos são indicadores planejados para identificar parâmetros que se relacionam a grupos científicos e tecnológicos em nível nacional. Geralmente são usados no processo de tomada de decisão em níveis estratégicos.
} 


\section{A. Compreender a contribuição do progresso técnico ao crescimento econômico}

A importância e a contribuição do progresso técnico ao crescimento econômico têm sido reafirmadas de maneira constante desde o trabalho inovador de Robert Solow ${ }^{1}$. Ele descobriu que somente uma pequena parte do crescimento econômico per capita nos Estados Unidos estava relacionada à mãode-obra e a investimentos de capital. Dessa forma, ele chegou à conclusão de que uma proporção maior desse crescimento era devida à mudança técnica. Outras pesquisas mostraram que muitos fatores, além da mudança técnica, também contribuíram para o aumento da produtividade. Nathan Rosenberg ${ }^{2}$ faz referência a vários estudos que indicam outros fatores significativos, como as economias de escala e as mudanças na qualidade da mão-de-obra. Apesar disso, todos esses estudos mostram que, de fato, o progresso técnico contribui de maneira considerável para o crescimento econômico.

\section{B. Responder a perguntas sobre políticas}

Os indicadores podem ajudar a responder às seguintes perguntas sobre políticas:

- Qual é o nível de interação entre as instituições de pesquisa financiadas pelo governo, as universidades e as empresas privadas?

- Qual é o potencial de inovação desses setores?

- Qual é o nível de qualidade da pesquisa universitária?

- De que maneira nosso país pode ser comparado a outros países em relação à capacidade científica e tecnológica?

\section{Realizar as seguintes funções}

- Monitorar o desempenho do sistema de C\&T.

- Avaliar o sistema e modificar a alocação de recursos para melhorar a eficiência do sistema de C\&T.

- Justificar ou negociar os orçamentos para C\&T.
- Oferecer insumos para o estabelecimento de políticas de C\&T.

\section{Apoiar as seguintes atividades}

- Estabelecimento de políticas de C\&T.

- Prestação de assessoria a ministros e a outros altos funcionários.

- Prestação de contas aos contribuintes que financiam atividades de C\&T.

- Análise do sistema nacional de inovações.

\section{QUESTÕES, DÚVIDAS E DESAFIOS}

Não existe dúvida alguma de que as razões anteriormente apresentadas são válidas para a maioria dos países. Como resultado disso, poderíamos cair na tentação de concluir que todos os países deveriam construir o mesmo conjunto de indicadores estratégicos. Esse não é o caso, porque, de fato, existem indicadores que são úteis para os países avançados, mas não para os países em desenvolvimento.

Um dos conjuntos de indicadores estratégicos mais conhecidos está representado pelas 89 tabelas publicadas pela $\mathrm{OCDE}^{3}$. Esse número representa dois grandes grupos de indicadores: os insumos e os produtos do sistema nacional de inovação. Os indicadores de insumos são representados pelos recursos gastos em pesquisa e desenvolvimento (P\&D), como os recursos humanos e financeiros. Os indicadores de produtos são representados pelas patentes e pelo balanço dos pagamentos despendidos em tecnologia.

Muitos países que procuram aperfeiçoar seus conjuntos de indicadores podem decidir simplesmente reproduzir tais indicadores, na esperança de que eles possam satisfazer suas necessidades. Essa poderia ser uma das etapas necessárias no processo de aprendizagem sobre como construir indicadores de C\&T, e essa é uma das linhas de abordagem adotadas pelo Brasil. Por motivos óbvios, não é possível deter-se nessa etapa, esperando que apenas isso trará resultados benéficos para o país. Isso porque os números selecionados pelos países da OCDE implicam premissas que não se aplicam neces- sariamente a todos os países do mundo. Algumas dessas premissas são:

\section{A. Os países têm suficiente reserva de conhecimento incorporado nos seus recursos humanos}

Se tomarmos os quatro ou cinco países mais desenvolvidos e ainda a China e a Rússia, veremos que os seus recursos humanos, sem dúvida alguma, detêm uma parte significativa da reserva atual de conhecimento científico e tecnológico. Também os países com alta renda per capita geralmente têm grande proporção de cidadãos com níveis educacionais elevados que detém um conhecimento substancial em C\&T.

Tais características tornam compreensíveis que seus indicadores sejam baseados em estatísticas de pesquisa e desenvolvimento, porque a maior parte deles tem recursos humanos bem treinados que se dedicam a atividades de $P \& D$. Esse não é o caso dos países menos desenvolvidos, nos quais a etapa anterior relativa ao sistema educacional, que permite desenvolver recursos humanos capazes de desempenhar atividades de P\&D, também deve ser o foco dos indicadores.

\section{B. A única maneira de alcançar o progresso é alargar a fronteira do conhecimento e aplicá-lo ao desenvolvimento de novas tecnologias}

Para os países avançados que já aplicam grande parte da reserva de conhecimento existente, alcançar o progresso significa alargar a fronteira do conhecimento através de atividades intensas em pesquisa e desenvolvimento. Para os países menos desenvolvidos, que não utilizam todo o conhecimento disponível na atualidade, é possível alcançar o progresso mais rapidamente concentrando-se no uso do conhecimento disponível, em vez de tentar desenvolvê-lo por meio de P\&D.

\section{O crescimento econômico (através do desenvolvimento tecnológico) pode solucionar a maioria dos problemas}

Nos países avançados, a maioria das pessoas pode ter uma vida digna, e o sistema de bem-estar social oferece uma ampla rede de assistência para os menos afortunados. Manter um sistema 
que funciona bem depende em grande parte do crescimento econômico alcançado através da inovação que gera os desenvolvimentos tecnológicos. Esse não é o caso de muitos outros países. Embora o crescimento econômico seja realmente o centro das preocupações, os padrões de crescimento que podem concretamente beneficiar a maioria da população, reduzindo as desigualdades e melhorando a situação de milhões de cidadãos que ainda vivem à margem do sistema econômico moderno, constituem uma mudança necessária que ainda está por vir. Em todos esses países, uma das dimensões que a política científica e tecnológica também deve considerar é como contribuir para o processo de "crescimento social".

\section{UMA PROPOSTA DE ANÁLISE}

Para poder desenvolver indicadores que sejam significativos para as realidades nacionais, os países interessados precisam adotar uma estratégia em duas direções. Por um lado, os países devem simplesmente tentar reproduzir aqueles indicadores. Essa é a etapa típica de "aprender fazendo". Ao seguir a metodologia da OCDE e, de fato, trabaIhar para desenvolver determinados indicadores, os especialistas em cada país poderão absorver a metodologia, os indicadores e as suas limitações. Por outro lado, e de maneira simultânea, os países devem trabalhar para criar marcos alternativos que respondam mais adequadamente às suas necessidades específicas. Isso poderia aplicar-se até mesmo a muitos países da OCDE que compartilham algumas características com países menos desenvolvidos.

Os parágrafos a seguir abordam essa segunda linha de ação e propõem um marco possível para analisar elementos dos sistemas de C\&T que não estão incluídos no enfoque da OCDE, mas que poderiam oferecer novos insights para o estabelecimento de políticas.

\section{A. O dilema das sociedades democráticas}

O ponto de partida do marco proposto é um dilema que todas as sociedades democráticas enfrentam. Com muita freqüência, negligencia-se o fato de que o crescimento econômico não significa necessariamente melhoria na qualida- de de vida da sociedade. De fato, se o crescimento econômico traz a destruição ambiental, por exemplo, o resultado final poderá ser uma deterioração da qualidade de vida*.

\section{B. Igualdade e eficiência: uma barganha necessária?}

Uma das melhores propostas sobre esse dilema foi apresentada pelo economista Arthur M. Okun ${ }^{4}$. Ele afirma que: "A sociedade norte-americana proclama o valor de cada ser humano. Todos os cidadãos têm assegurados uma justiça igualitária e direitos políticos iguais. Todos têm a promessa de conseguir uma resposta rápida dos bombeiros e acesso aos monumentos nacionais. [...] Ao mesmo tempo, nossas instituições dizem 'procure um emprego ou morra de fome', 'tenha sucesso ou sofra'. Elas nos incentivam a sermos economicamente melhores que os nossos vizinhos, depois de nos dizer que socialmente devemos nos manter no mesmo nível. Elas outorgam prêmios que permitem aos grandes ganhadores alimentar melhor seus animais de estimação que os perdedores podem alimentar seus filhos".

De fato, organizar o tecido social e econômico de uma sociedade exige barganhas necessárias em que uma meta realista deve ter como propósito obter as melhores condições possíveis em vez de acordos ideais. As sociedades sujeitas a regimes autoritários, sem dúvida alguma, enfrentarão mais contradições que as sociedades democráticas, mas, mesmo onde existam condições ideais para a democracia, um dilema inevitável persistirá. Por um lado, as sociedades garantem a igualdade de direitos a todos. $\mathrm{O}$ aspecto mais representativo desse princípio é outorgar o direito de voto a todos os cidadãos, independentemente de renda, raça, sexo ou qualquer outra característica indivi-

\footnotetext{
* A qualidade de vida pode ser afetada de várias maneiras e pode ser alcançada por meio de ações que: i) reduzam a desigualdade de renda; ii) reduzam as diferenças das condições de vida resultantes da renda, oferecendo sistemas de saúde pública, programas habitacionais para os pobres ou programas de proteção ambiental; iii) reduzam a desigualdade de oportunidades, oferecendo amplo acesso à educação básica ou através de legislação concebida para eliminar a discriminação racial, de sexo ou de qualquer outro tipo.
}

dual. Por outro lado, o sistema produtivo deve ser eficiente, e, no processo de procurar uma alocação eficiente dos agentes econômicos, remunera-se meIhor o trabalhador mais competente e capacitado, bem como investe-se mais nos equipamentos de produção mais avançados e confiáveis. O trabalhador menos competente recebe um salário menor, se tanto. Os equipamentos menos avançados são vendidos a preços reduzidos, ou rejeitados junto com a empresa, se esta não encontrou um nicho para competir. Dessa maneira, as atividades produtivas de uma sociedade conduzem a uma desigualdade crescente. Essa disparidade, entretanto, não é o resultado de um planejamento intencional. Muito pelo contrário, essa desigualdade é o resultado indesejável da busca por alcançar um uso eficiente dos recursos que beneficiam toda a economia. De acordo com Okun, existe uma barganha clara entre a eficiência e a eqüidade, e o desafio é encontrar o justo equilíbrio entre essas duas aspirações tão desejadas.

\section{Os principais protagonistas na sociedade}

Com exceção dos fenômenos naturais, todas as transformações que ocorrem em uma sociedade ${ }^{*}$ são realizadas por indivíduos e instituições. À medida que procuramos formas para entender as trocas envolvidas nas atividades que desempenhamos, acredito que aqueles que estão envolvidos em moldar os acontecimentos pertencem a um dos cinco setores a seguir (cuja classificação institucional segue as recomendações do Manual de Frascat $)^{)}$:

\section{- Negócios}

- Governo

- Universidade (educação superior)

- Organizações sem fins lucrativos

- Exterior

* Para a situação específica que quero discutir, sociedade significa o país. 
Por que selecionamos esses cinco? Existem mais? Sem entrar no mérito se esses são setores relevantes ou não, sustento que essa classificação particular é uma representação muito próxima da realidade e tem as características necessárias para permitir o avanço das proposições deste texto.

\section{Os papéis dos protagonistas na sociedade}

Para o objetivo deste trabalho, optei por representar a sociedade por meio de um modelo bidimensional, no qual as dimensões são as seguintes (figura 1): - tipos de bens produzidos (públicos ou
privados);

- relação com o conhecimento (usuário ou produtor).

Escolhi esse modelo porque ele sintetiza os aspectos mais críticos enfrentados pelas sociedades: a questão do desenvolvimento econômico e os desafios de construir uma sociedade eqüitativa.

A questão do desenvolvimento econômico deve sua própria existência ao conhecimento. Já se demostrou há muito tempo que grande parte do desenvolvimento econômico é alcançado mediante a agregação de conhecimentos. Ao mesmo tempo em que todos os protagonistas geram e usam o conhecimento, alguns se dedicam à geração de conhecimentos, enquanto outros ocupam-se sobretudo em fazer o melhor uso dele. A distinção entre produtores e usuários do conhecimento não é irrelevante, porque permite identificar os fluxos do conhecimento. Os sistemas sociais que favorecem esses fluxos tendem a ser mais eficientes, criativos e inovadores.

A questão da construção de uma sociedade eqüitativa depende do equilíbrio entre a produção de bens públicos e de bens privados. A barganha entre eqüidade e eficiência, mencionada por Okun, está estreitamente relacionada à produção desses dois tipos de bens. Quanto maior for a produção de bens públicos, maior será a contribuição para a eqüidade, desde que algumas condições sejam satisfeitas.

\section{FIGURA 1 \\ O papel dos protagonistas no uso e na produção de conhecimento de interesse público}

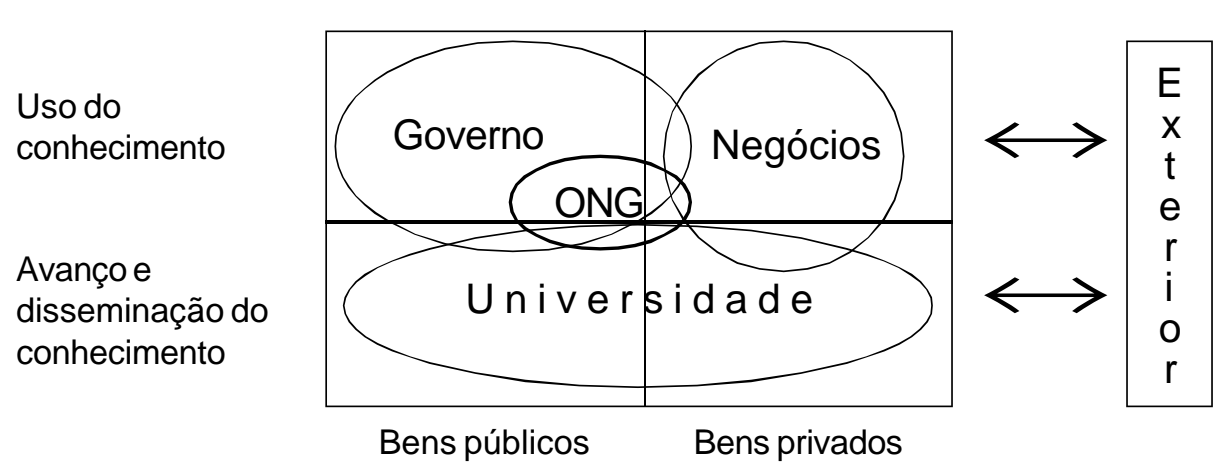

A principal distinção entre os dois tipos de bens é a seguinte: Se eu consumir um bem privado, como um hambúrguer, ninguém mais poderá consumi-lo. No caso de um bem público, como a defesa nacional, o fato de eu consumi-lo não impede que outros também o façam. Quer dizer, o fato de eu estar protegido pelo sistema de defesa nacional, não diminui a proteção de outros cidadãos brasileiros. Um bem privado é exclusivo; seu consumo por uma pessoa exclui outras de fazê-lo. Um bem público é não-exclusivo; seu consumo por uma pessoa não impede outras de também consumi-lo ${ }^{6}$.

Um aspecto interessante dos bens públicos é que, uma vez produzidos, podem ser consumidos por um grande número de pessoas. Nesse sentido, esse aspecto é similar ao milagre da multiplicação dos pães. Como já mencionei anteriormente, uma vez que um sistema de defesa seja estabelecido, todos poderão usufruir igualmente de seus benefícios, independente de riqueza, sexo, raça ou outra característica pessoal. O mesmo se aplica a uma campanha de saúde pública, ou a um programa de proteção ambiental que garante acesso à beleza da natureza, ao ar fresco, à água limpa, ao lazer e ao alimento dos rios, entre outros benefícios gratuitos.

No entanto, uma determinada situação pode deteriorar as características milagrosas dos bens públicos. Os bens públicos também precisam ser produzidos de maneira eficiente, o que permanece, em grande parte, um problema sem solução. Não podemos discutir esse tema tão complexo neste texto, mas é importante observar que a produção eficiente de bens públicos é um desafio muito maior que a produção eficiente de bens privados. Além do mais, se os bens públicos forem produzidos sem eficiência, outros tipos de desigualdades poderão surgir.

Baseados nas distinções apresentadas, vamos localizar cada protagonista no espaço bidimensional (figura 1).

\section{Negócios (setor privado)}

Os negócios se referem à produção de bens privados consumidos pela sociedade. Sua principal atividade é produzir bens como carros, bicicletas, comida enlatada, alimentos naturais, roupas, medicamentos etc. Devido ao seu papel de produção de bens privados, são conhecidos freqüentemente como setor privado. De maneira geral, são os usuários do conhecimento acumulado durante anos nos seus respectivos campos de atuação. Alguns, no entanto, especialmente os que operam na fronteira do conhecimento, estão também envolvidos na própria produção do conhecimento.

\section{Governo}

O governo também produz bens consumidos pela sociedade. Entretanto, produz bens públicos, que em muitos casos não podem ser identificados tão facilmente quanto os bens privados. Alguns exemplos são o corpo de bombeiros, a segurança nacional feita pelo exército, o sistema de saúde pública, a educação pública, a justiça, a rede de transportes etc. 
Por que o setor privado produz uma coisa, enquanto o governo produz outras diferentes? O setor privado produz bens que são escassos na sociedade, assim as pessoas pagarão para obtê-los. Se o preço que os consumidores estão dispostos a pagar for maior que os custos da produção, o setor privado se desenvolverá. Usando o mesmo raciocínio, se o preço não cobrir os custos, a produção não existirá. Suponhamos, entretanto, que o setor privado não esteja disposto a produzir porque a produção não é lucrativa, mas as pessoas se beneficiariam enormemente dela. Esses são os casos em que o governo deve intervir e produzir esses bens.

Com respeito ao conhecimento, o governo tem um papel significativo como fonte de financiamento, um papel considerável como produtor e um papel ainda mais proeminente como usuário.

\section{Universidade}

A universidade é o principal produtor de um dos temas centrais deste trabalho: o conhecimento. Em um certo sentido, a universidade poderia ser identificada como parte do governo, como produtor de um bem público. No entanto, o impacto do conhecimento na nossa sociedade é tão grande, que justifica tratar a universidade separadamente como protagonista influente na sociedade. Seu principal papel é produzir e disseminar o conhecimento através de atividades relacionadas à pesquisa, ao ensino e à extensão.

4. ONG (organizações não-governamentais ou sem fins lucrativos)

As organizações não-governamentais aparecem onde quer que exista uma necessidade não atendida pelos três protagonistas anteriores. O mais comum é que operem na produção de bens públicos, utilizando o conhecimento existente ou realizando pesquisas para expandir a fronteira do conhecimento em campos em que haja uma missão a cumprir. Algumas dessas organizações podem operar em áreas relacionadas aos bens privados, mas, nesses casos específicos e para fins de análise, é mais apropriado tratá-las como negócios.

\section{FIGURA2}

Relações e disseminação de conhecimento entre os protagonistas de um sistema de C\&T

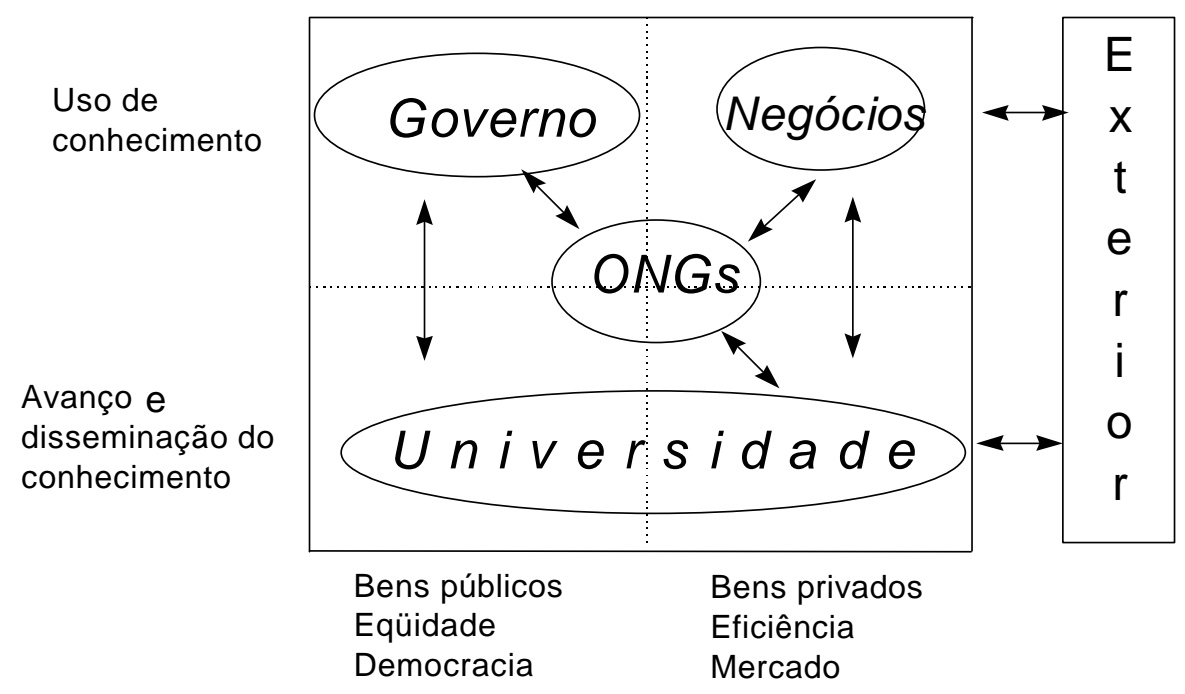

\section{Exterior}

Os governos estrangeiros podem freqüentemente enviar assistência técnica ou financeira para uma economia. Muitas empresas multinacionais transferem tecnologia e injetam recursos financeiros em unidades de produção localizadas em outros países. Os cientistas estrangeiros são possivelmente a principal fonte de transferência de conhecimento (acadêmico) entre países, considerando que o intercâmbio e a cooperação nesse campo não são afetados pelas patentes, segredos comerciais ou marcas registradas. $O$ mesmo ocorre com as ONGs, nas quais um volume significativo de recursos pode ser transferido dos países avançados para os países em desenvolvimento. Como se pode observar, o quinto protagonista compreende os quatro outros provindos de um país diferente.

\section{APLICANDO O MARCO CONCEITUAL}

As formas em que o marco pode ser aplicado serão limitadas somente pela criatividade das pessoas. Os dois aspectos principais que devem orientar a escolha dos indicadores são as relações entre os protagonistas e a posição que cada um ocupa na produção de bens públicos e privados.
A. Relações (o tamanho dos círculos em volta de cada protagonista na figura 2 , que representa a esfera possível de ação dos protagonistas, foi reduzido para permitir espaço para as setas; os tamanhos da figura 1 são mais precisos).

Alguns exemplos entre as numerosas características do sistema nacional de C\&T que podem ser analisados através de relações são:

1. Até que ponto o conhecimento transferível livremente do exterior está sendo efetivamente transferido. Isso poderia ser representado pela força das relações entre as universidades nacionais e estrangeiras.

2. Até que ponto o avanço do conhecimento alcançado na universidade está sendo transferido para as instituições governamentais e as empresas. Isso poderia ser representado pela força das relações entre a universidade, o governo e as empresas.

\section{B. Posição de cada protagonista na pro- dução de bens públicos e privados}

Cada um desses protagonistas irá se posicionar em uma esfera determinada entre a produção de bens privados e públicos (figura 3, a seguir). 
Isso será o resultado das escolhas políticas das instituições que determinam uma direção, do mesmo modo que as instituições definem suas missões e selecionam as formas de atingi-las. Se isso deve ser determinado por um organismo central que estabelece as políticas, ou se deve ser feito de forma descentralizada, é uma questão interna que os países terão de resolver individualmente. A utilidade do marco proposto é chamar a atenção para essa importante dimensão, que normalmente não é incluída no processo de tomada de decisão. Vale a pena mencionar algumas das possíveis razões que podem influenciar as escolhas políticas, para que essas escolhas possam efetivamente ser baseadas em razões sólidas.

\section{Razões ruins}

- Porque a economia "globalizada" assim o exige.

- Porque os países mais avançados fazem as coisas dessa maneira.

- Porque sempre fizemos as coisas desse jeito.

\section{Developing strategic indicators on science and technology: the main issues}

\begin{abstract}
This paper propounds that strategic indicators for less developed countries should take into consideration the specificities of these countries, hence should not just replicate the indicators used by the OECD. With this purpose, it uses a new conceptual framework stressing the importance of a balance between economic efficiency and social welfare. It lists several sensible reasons to develop strategic indicators, shows how each of them is based on assumptions that are not necessarily valid to all countries, and shows why a new conceptual approach is needed. Then, after discussing the main features of the proposed model, it shows how the new framework can help identifying the kinds of new indicators needed. Finally, the paper suggests how the approach could also be useful to a project trying to evaluate scientific publications.
\end{abstract}

\section{Keywords}

Science and technology indicators.

\section{FIGURA 3}

Escolhendo uma posição entre a produção de bens públicos e a produção de bens puramente privados

\section{Razões não tão ruins}

- Porque tenho um bom coração e quero ajudar as pessoas.

\section{Boas razões}

- Necessidades sociais do país.

- Possibilidades tecnológicas de um campo específico de pesquisa.

\section{- Efeitos em cascata.}

- Existem bens públicos que podem ser melhorados com essa ação particular e que irão melhorar o bem-estar de toda a sociedade.

\section{CONCLUSÃO}

Este trabalho tentou discutir as principais questões envolvidas na produção de indicadores nacionais para a ciência e a tecnologia. A principal proposta aqui indicou que, utilizando o marco conceitual sugerido, os países menos desenvolvidos devem procurar outros indicadores, além dos 89 selecionados pela OCDE. Este trabalho enfatizou os indicadores nacionais, mas o marco conceitual também pode ser útil para o projeto de avaliação da literatura científica do projeto SciELO - Scientific Electronic Library Online, auxiliando a análise dos seguintes aspectos:

- que valor deve ser financiado com recursos públicos;

- os efeitos do projeto em relação às "iguais" oportunidades para todos os participantes e a eficiência do sistema como um todo;

- de que maneira o projeto alcança o equilíbrio entre "eqüidade" e eficiência.

\section{REFERÊNCIAS BIBLIOGRÁFICAS}

1. SOLOW, Robert. Technical change and the aggregate production function. Review of Economics and Statistics, Aug. 1957.

2. ROSENBERG, Nathan. Inside the black box: technology and economics. New York: Cambridge University Press, 1982.

3. OECD. Main science and technology indicators. Paris: OECD, 1996.

4. OKUN, Arthur M. Equality and efficiency: the big tradeoff. Washington: The Brookings Institution, 1975. p. 1.

5. OECD. Manual de Frascati. Paris: OECD, 1993. p. $47-66$.

6. NICHOLSON, Walter. Microeconomic theory: basic principles and extensions. 3. ed. Chicago: Dryden Press, 1985. p. 706-9.

\section{Edson Kenji Kondo}

Ph.D., Chefe da Divisão de Indicadores em Ciência e Tecnologia. Conselho Nacional de Desenvolvimento em Ciência e Tecnologia (CNPq).

ekondo@cnpq.br

Tradução do inglês de Amy Herszenhorn Revisão da tradução de Irati Antonio 